\title{
Nostalgia Promoting Pro-Social Behavior and Its Psychological Mechanism
}

\author{
Ya Li \\ Management School, Jinan University, Guangzhou, China \\ Email: liya_job@163.com
}

Received 8 October 2015; accepted 26 October 2015; published 29 October 2015

Copyright (C) 2015 by author and Scientific Research Publishing Inc.

This work is licensed under the Creative Commons Attribution International License (CC BY). http://creativecommons.org/licenses/by/4.0/

(c) (i) Open Access

\begin{abstract}
Nostalgia is a kind of socio-emotional that refers to personal sentimentality caused by recalling objects, people, places, experiences or feelings from the past. Studies have found nostalgia has a positive effect on the mental health and can also promote pro-social behavior of individuals. This paper reviews the promoting effect of nostalgia on the altruism, commonweal and social rule and relational pro-social behaviors. Moreover, the author puts forward possible psychological mechanisms and theoretical explanations. Future studies should further investigate the relevant psychological mechanism and moderated effects of individual differences, the study on the refinement of the nostalgia and pro-social behavior researches.
\end{abstract}

\section{Keywords}

\section{Nostalgia, Pro-Social Behavior, Promoting}

\section{Introduction}

With the speed of modern society, people in this rapidly changing era are becoming fonder of nostalgia. The repeated singing of classic songs and the pursuit of youthful nostalgia movie always set off a boom of "Recalling" in the crowd.

"Nostalgia" was introduced by the Swiss physician Johannes Hofer, the initial definition of nostalgia was similar to the now "Homesickness" means and was considered that it was a medical or neurological disease. Nostalgia was once regarded as brain dysfunctions, a form of melancholia or depression [1]. However, people's understanding of nostalgia now is completely different from its original meaning. In some Western dictionaries, "nostalgia" is defined as "an eagerness to go back to an environment or an event" or "when you remember the good times of past, a mixture of sadness, joy and love". The author in this article refers to the Western definition of nostalgia. Researchers suggest nostalgia, a sentimental longing for the past, is a self-relevant and social emo- 
tion [2]. In recent years, many psychological studies have found nostalgia can serve as a repository of positive affection, which can improve self-esteem [3], promote optimism [4], foster creativity, and so on and so forth. Researchers analyzed the content of the described of nostalgia, and the results revealed that nostalgic episodes typically involved interactions between the self and close others such as family members, friends, and romantic partners, it served vital relational functions: It bolstered social bonds and increased perceived social support [5].

Pro-social behavior refers to humility, helping, cooperation, and sharing, even it needs self-sacrifice for benefit of others, and is an important foundation for maintaining good relations between people [6]. Carlo and Randall [7] divided pro-social behavior into 6 types: altruistic, compliant, emotional, dire, public, and anonymous. They all have their own characteristics, but they also have something in common, that is they all help others, and are beneficial to others' actions and intentions. Research of Gino and Desai [8] found that recalling childhood memories influenced the extent to which we see ourselves as morally pure-a psychological state that resulted from a person's view of the self as clean from a moral standpoint and through which a person felt innocent and virtuous. This heightened sense of moral purity, in turn, leads to greater pro-social behavior. What's the impact of nostalgia on pro-social behavior, and how did it happen? This review summarizes studies of nostalgia and pro-social behavior, discusses the role of nostalgia in promoting pro-social behavior, psychological mechanism and research prospects for the future.

\section{Nostalgia Promotes Pro-Social Behavior}

Researchers have been classified according to the different perspective on nostalgia, Baker and Kennedy [9] according to the source of nostalgia divided it into real nostalgia, simulations and collective nostalgia. But on the whole, nostalgia is a self-centered, a mix of positive and negative complex emotional experience when recalling past. There is no authoritative theory for this type of research can learn from, and the focus of this paper aims to explore the relationship between nostalgia and pro-social behavior, therefore this paper has yet to carefully distinguish between the nostalgic types, future research can be expanded in this regard.

This classification of pro-social behavior is quoted from Zhang Qingpeng and Kou Yu [10]. They divided it four categories: altruism, commonweal and social rule, relationship and personal trait pro-social behavior. The category of specific acts can be found in Table 1 [11]. Judging from the existing research, nostalgia and pro-social behaviors of individual research mainly deals with altruism, commonweal and social rule, relationship pro-social behaviors, there is no study of nostalgia and personal traits of pro-social behavior.

\subsection{Nostalgia Promotes Altruism Pro-Social Behaviors}

Altruism pro-social relate mainly to the interests of others, and may even have to pay a price, donate, help, care belongs to this category. In the United States, alumni giving has become a significant source of university fund-

Table 1. The 4 dimensions of pro-social behavior.

\begin{tabular}{|c|c|c|c|}
\hline Altruism & Commonweal and Social Rule & Relationship & Personal Trait \\
\hline heroic & commonweal behavior & modestly decline & pleasant \\
\hline rescue & rapport & do no harm & compliment \\
\hline development skills & benefit to groups & concern others & loyalty \\
\hline donation & keep the rule & reception & sympathy \\
\hline look after & positive suggestions & appreciating & tolerance \\
\hline help & return & apologize & generous \\
\hline present & observe customs & comfort & \\
\hline \multirow[t]{4}{*}{ physical support } & take responsibility & cooperation & \\
\hline & considerate & share & \\
\hline & social morality & improve friendship & \\
\hline & environmental protection & initiate a friendship & \\
\hline
\end{tabular}


ing and one of the important strategies and mitigation education costs. Most University attaches great importance to the alumni, often organize various alumni activities to strengthen links between alumni and their alma mater to mobilize them to contribute to the school. This alumni emotion is inseparable from nostalgia. Psychological study found that nostalgia can promote individuals, such as donations, helpful altruism pro-social behaviors.

In Ford and Merchant [12], nostalgic charity appeals evoke higher levels of emotions and donation intentions than non-nostalgic appeals. The authors developed two advertisements inviting donations for Public Broadcasting Service (PBS). The first utilized a nostalgic appeal by invoking memories of the past, another is a general advertising without nostalgic information. Participants will see a random ad, after completing a four-item of donor intent questionnaire to test their willingness to donate. Results showed that when compared to the nonnostalgic advertisement, the nostalgic advertisement evoked significantly higher levels of emotions and donation intentions compared to general advertising. But it is worth noting is that this study's subjects are mostly older people, average age about 55 years old. Zhou Xinyue and others [13] developed a more detailed study also provides evidence that nostalgia promotes charitable intentions and behavior. Their research subjects included Chinese undergraduate students, expatriates and overseas students residing in Chinese University. Researchers asked half the participants to recall the most nostalgia events and bring it to one's own feelings, and write it down in detail; the other half of the subjects as control group were asked to recall general events that happened last week. Next, participants were provided with a one-page description of a nonprofit organization, allegedly as part of an unrelated study. This fictitious organization was named "Half the Sky Foundation," and the one-page description explained that its mission was to help young victims of the May 2008Wenchuan earthquake. Participants were then asked to write down the number of hours that they planned to volunteer for this charity and the amount of money that they planned to donate to this charity. Results showed that nostalgic (vs. control) participants intended to spend more time volunteering for charity and intended to donate more money to charity. After that, researchers further improve this experiment-substitute actual monetary donations for intentions to donate. Participants first completed a series of laboratory tasks. These tasks were unrelated to the subsequent study but provided a pretext for paying participants a fee. Participants were told that they would receive a fee for performing the laboratory tasks and then received $7 \mathrm{RMB}$ in $1 \mathrm{RMB}$ notes. When participants were preparing to leave the laboratory, another experimenter entered the room and showed them a printed charity appeal for the Half the Sky Foundation. This appeal either contained nostalgic cues or did not contain nostalgic cues. To assess charitable giving, a collection box had been placed near the exit of the laboratory. The amount of money that participants placed in the box served as index of charitable giving. Results are consistent with previous, participants who were exposed to the nostalgic appeal contributed more money than did participants exposed to the non-nostalgic appeal, nostalgic appeals increased tangible charitable behavior.

Helping behaviors are representative of altruism pro-social behaviors, helping behavior can often be observed in society and, more specifically, it refers to the protection and promotion of the interests of others. Stephan and Wildschut, investigated the nostalgic effect on helping behavior [14]. First of all, researchers trigger the subjects by memories of nostalgia, next, a staged mishap provided the opportunity to offer help. An experimenter (who was unaware of the experimental condition to which participants had been assigned) walked into the room holding a folder of papers and a box of pencils, and spilled the pencils in front of the participant. The number of pencils picked up by the participant constituted the measure of helpfulness, then, researchers will create with "sudden incidents" to study the subjects of helping behavior. Results showed that participants in the nostalgia condition gathered more pencils than those in the control condition. The effect of nostalgia on the number of gathered pencils remained significant after controlling for PA and NA in ANCOVAs. This suggests that nostalgia can promote people's helping behavior.

\subsection{Nostalgia Promotes Commonweal and Social Rule Pro-Social Behavior}

Commonweal and Social rule pro-social behavior relate mainly to keep the social rules and concern interests of public, including acts of commonweal behavior, obligation, benefit to groups, and so on. About commonweal behavior, an overseas volunteers of research found, when researchers asked volunteers why they chose to come back to the nonprofit, they relayed vivid and colorful memories of joy and affection they had received from the locals of the country they had been serving. This nostalgia by raised of memories makes volunteers want to maintain the relationship between them and nonprofit organizations, or people who get along with their volun- 
teer activities [15]. Related research on the nostalgia and organizational level showed nostalgia can bolster social links among members and organizations, promote belongingness. It is conducive to maintaining cooperation between members and leaders, and organizational citizenship behaviors (organizational citizenship behavior, OCB).

Studies have shown that, it is essential for the proper functioning of organizations that individuals focus on the welfare of the collective and its members rather than indulging their own interests [16]. Yet, the display of such cooperative behavior is undermined when members find that their social connectedness to the organization and its authorities (e.g., supervisors, managers, leaders) is compromised [17]. According to relational justice models, high procedural justice contributes to a sense of social connection with the collective and its authorities, whereas low procedural justice engenders a sense of exclusion. Hence, low procedural justice damages cooperation.

However, Dijke et al. [18] study finds nostalgia buffers (i.e., weakens) the deleterious impact of low (compared to high) procedural justice on organizational citizenship behavior (OCB) and cooperation with authorities. Study 1 using survey method, recruit 130 staff, they be employed in an organization and have a supervisor (i.e., not be self-employed).Participants will respond the procedures justice, OCB, and nostalgia proneness scales online. Results found that OCB was not significantly predicted by procedural justice, the Nostalgia Proneness $\times$ Procedural Justice interaction predicted OCB. The association between procedural justice and OCB was significant among employees low, but not high, in nostalgia proneness. In other words, when procedural justice is low, employees who are high (compared to low) in nostalgia proneness should display increased levels of OCB. When procedural justice is high, however, employees' level of nostalgia proneness should not be associated with OCB. This means that, nostalgia seems to be the indirect strategy to deal with the low procedural justice, and maintains cooperation between the members and organizations. They conducted four experiments after that, manipulating the subjects’ nostalgia and procedural justice, and then measuring participants' support, cooperation intention and behavior. Results showed that regardless of whether nostalgia was operationalized in terms of an experimentally induced emotional state or as chronic individual differences in nostalgia proneness, nostalgia buffered the harmful effect of low procedural justice on self-reported cooperation, on intentions to cooperate, on support for the authority, and on objective cooperative behavior.

There is other evidence shows that collective nostalgia is a group-level emotion, which is beneficial to the group [19]. For example, increasing the positive comments and support for members of the group, sacrificing money to punish people who are bad for the group members, and so on. These studies indicate that nostalgia can make individuals more considerable to the interests of organizations or groups, and showing more commonweal and social rule pro-social behavior.

\subsection{Nostalgia Promotes Relationship Pro-Social Behaviors}

Relationship pro-social behaviors involve building and maintaining positive relationships in social communication, such as do no harm, acceptance and friendship.

In the community, certain special groups, such as obesity, often because of their weight problems and then suffered slander, forced to face a lot of prejudice and discrimination. Public have formed a kind of negative stereotypes, that being overweight or obese is laziness, lack of energy, short of discipline and competence, and this kind of weight bias in employment, health and educational fields would evolve into all kinds of injustice, sustained injury and the resulting sense of shame will eventually damage the quality of their lives [20].

However, Turner and his colleagues [21] have found that nostalgia can reduce people's prejudice and promote positive outgroup attitudes, acceptance of their members. When individuals become nostalgic about a known outgroup member, an increased sense of social connectedness will result in greater inclusion of that outgroup member in the self, inclusion of others in the self is a marker of interpersonal closeness, inclusion of an outgroup member in the self will result in the inclusion of the entire outgroup in the self. A potential benefit of this is a more positive outgroup evaluation [22].

Turner and others found that nostalgia can improve attitudes toward persons who are overweight to reduce weight stigma [21]. Researchers asked participants (nostalgia condition) "try to think of a past event involving an overweight person that makes you feel most nostalgic, try and immerse yourself into this nostalgic event, remembering what it was like and how you felt at the time you interacted with the overweight person”. Participants in control condition recalled a past event involving an overweight person that is ordinary, and bring to 
mind an objective record of this event. Results are consistent with the hypothesis, nostalgic participants relative to control participants held more positive attitudes toward persons who are overweight. Nostalgia promotes the acceptance of the groups of overweight, improved attitudes towards overweight people--encompassing affective, cognitive, and behavioral components. In a subsequent study [23], they targeted groups moved from overweight to mental illness, and used a subtle yet impactful manipulation developed by Hepper et al. [3] to induce nostalgia. Results are consistent with previous research; nostalgic (relative to control) participants evaluated persons with mental illness more favorably. This shows that the prejudice reduction function of nostalgia is not limited to a specific group, nostalgia can increase acceptance of outgroup members and improve the positive attitude from the individual to the group, promoting relationship pro-social behaviors.

\section{The Psychological Mechanisms and Theoretical Explanations of the Enhanced Pro-Social Behavior Caused by Nostalgia}

\subsection{Nostalgia Improve Approach Motivation}

Motivation can be seen as the direction and energy of people's behavior. Past studies have found that induced the motivation to help others will affect the process and results of helping behavior [24]. Studies have found that behavior is driven by two fundamental action tendencies: avoidance and approach, which reflects the interaction between the individual and the environment, and their coordination is critical to the adaptive functioning.

Gary [25] suggested organisms have two basic systems: behavioral approach system (BAS) and the behavioral inhibition system (BIS). Behavioral approach system also called behavioral activation system, which controls the desire and incentive motivation, provides the neuroanatomical substrate for appetitive or approach motivation. This system is sensitive to signals of reward or non-punishment, facilitating goals and behavior that are likely to lead to positive outcomes. The BAS underlies the experience of positive feelings such as hope, happiness, and elation. Behavioral inhibition system controls aversive motivation, withdraw and avoidance behavior, steering body away from things and stimulus in environment. This system is sensitive to signals of punishment or nonreward, inhibiting goals and ongoing behavior that are likely to lead to painful outcomes. It underlies the experience of negative feelings such as anxiety, sadness, frustration, and fear.

Pro-social behavior can be seen as one of social approach motives, it needs others emotional or physical proximity, and studies have shown that, people possessed appropriate interpersonal intimacy and dependency were more likely to help others [26]. Nostalgia makes the individual to experience a feeling of being protected, loved, reduced attachment anxiety and attachment avoidance [5] [7], narrows the psychological distance between people, and excites the behavioral approach system. In experiments such as Stephan [14], participants learned that they would have a brief conversation with another person (i.e., also a participant) who was located in an adjoining room. Ostensibly to prepare the room for this forthcoming interaction, the experimenter instructed participants to place two chairs (one for the participant and one for the other person) in a designated area within the room. The experimenter then left the room, supposedly to fetch the other person. Researchers took the distance between the two chairs as an index of approach social behavior. Results showed, participants in the nostalgia condition placed the two chairs closer together than did those in the control condition. Therefore, from the perspective of motivation, nostalgia can improve the approach motivation, narrow emotional distance, make the individual close to the others, and then show more pro-social behavior.

\subsection{Nostalgia Improve Social Identity}

Sierra and McQuitty have used social identity theory to explain consumer behavior of nostalgia [27], they believe the membership of a community may influence an individual's emotional and cognitive, and this affects nostalgic purchases. Social identity theory was first proposed by Tajfel and Turner [28], and its core idea is that social people seek to catalogue themselves and others into social categories by memberships, affiliation, age, gender, culture, and others. Members achieve or maintain a positive social identity to increase self-esteem, positive self-esteem comes from the comparison between ingroup and related outgroup [29]. The theory predicts that people form self-concepts based on both their social identity and their self-identity. Self-identity is the characteristic and trait that each person believes he or she possesses, such as knowledge of past, physical characteristics. Social identity is derived from accepting membership in a society, culture, or group. Such memberships, which contribute to self-image and self-satisfaction, help to define an individual's self-identity [30]. 
Tidwell [31] applied social identity theory to study on pro-social behavior in the nonprofit organizations, they found that those high in organizational identification are more likely to engage in volunteerism and contribute financially to their nonprofit. They suggested that as participants develop an identification with the organization, they begin to see themselves as integral to the collective and their fates intertwined. This sense of connectedness leads to less fear of exploitation and increased trust and empathy for the collective will also enhance organizational commitment and satisfaction, when their identification with the organization is salient, individuals would take into account the interests of the organization more than their own interests, showed more pro-social behavior.

Mael and Ashforth [32] found that college alumni who are high in organizational identification frequently engaged in pro-social behaviors on behalf of their alma mater. They made financial contributions, engaged in informal recruiting, and attended school functions to support their institution. Similarly, O’Reilly and Chatman [33] discovered corporate and student populations high in organizational identification engaged in pro-social behaviors geared toward furthering the goal and mission of their respective collectives. These behaviors included helping others and attending voluntary functions to enhance the organization's image. These studies have shown that social identity is beneficial to improving pro-social behavior.

Researchers found that nostalgia can help individuals to establish an identity, increasing social identity and self-identity. Nostalgia may be used as a mechanism by which individuals differentiate themselves from others, thereby solidifying their uniqueness [30], it can help people assess past of life and achievements and place themselves in a time and space reference which can give them a better understanding of their current identity. These emotional and cognitive responses to the past may help individuals understand their identity in the present [27]. Volkov and others [34] developed a conceptual models build on the PCM model (Psychological Continuum Model) [35], presents the path that nostalgic impact social identity. Researchers suggested that nostalgia through awareness, attraction, attachment and loyalty to impact the identification (see Figure 1). Nostalgia allows individuals to relive past experiences and memories and provokes the individual's sense of belonging to groups so as to enhance their sense of social identity. Of course, this is only a theoretical model also needs further empirical validation.

To sum up, nostalgia can induce a high self-awareness of self and group, enhance the social connectedness of individuals and groups and improve social identity, thus contributing to pro-social behavior.

\subsection{Nostalgia Improve Empathy}

Batson [36] suggested empathy is commensurate with the perceived welfare of others orientation of the emotional reactions of others, include compassion, mercy, kindness, soft hearted, easily moved, those kinds of emotions. His empathy-altruism hypotheses hold that consciousness of others misfortune or trouble would trigger two different emotional reactions: empathy and personal distress. Empathy is based on altruistic desire to want to help people reduce pain and excited to help. And personal distress is out of selfish motives trying to reduce their pain, though it can also lead to helping behavior, but the emotional response may also lead to individual choose to stay away from those who need help [36]. Individuals in personal distress showed fewer helping behavior if there was a chance to escape, because fleeing can reduce their pain doesn't require any spending, but individuals in empathy will help others even have a flight opportunity, because their aim is to alleviate the suffering of others. Many studies have proved that empathy can improve altruism helping behavior [37].

There is no doubt that, nostalgia can influence the emotion, some scholars are directly defined nostalgia as an emotional experience. Batcho [38] found that people with a high tendency of nostalgia have a stronger emotional

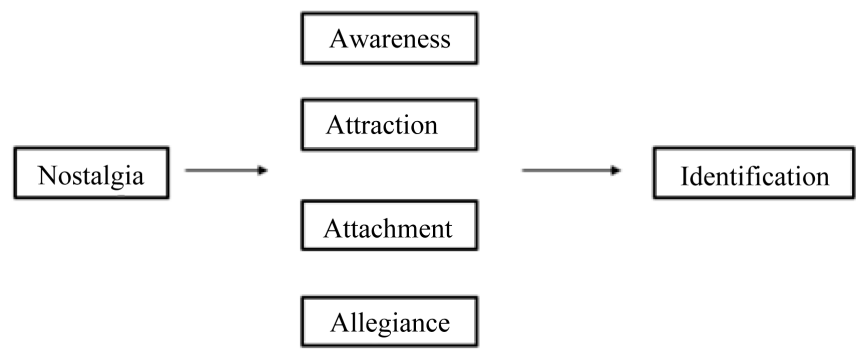

Figure 1. Conceptual Model: The role of nostalgia in determining consumers’ identification. 
experience, which means in a pleasant event experience more happiness, in a sad event also sadder. Nostalgia as a social emotion can bolster our social bonds [5], also has a positive impact on social support [39]. Previous research found that the strong sense of social connectedness is a precedent to show empathy to others [24]. Cordaro suggests that nostalgia will inspire empathy [40]. In the experiment, participants in the nostalgia condition were instructed to recall a nostalgic event, participants in the ordinary control condition were instructed to recall an ordinary event from their past. Next, researchers gave participants a handwritten essay ostensibly written by another student describing a physically painful experience, participants were led to believe that the essay was written by another student who was participating in the same experiment, and was asked to recall a recent important event. After reading this essay, each participant was given a brief questionnaire asking them to describe how sympathetic, warm, compassion ate, and tender they felt for the person that wrote the essay. Participants rated each of these on a 6-point scale. Ratings for each category were averaged to create an overall empathy score. Results show that participants in the nostalgia condition reported significantly higher levels of empathy than those in the control condition, in other words, immersing oneself in a nostalgic experience increases the level of empathy one feels for others. Zhou et al. [13] introduced in its study the empathy-altruism hypothesis, finding empathy (but not personal distress) qualifies as a potential mediator of the nostalgia effect on charitable giving. Therefore, the reason why nostalgia can promote pro-social behavior is that nostalgia nostalgic revisits memories of interacting with others, enhances social connectedness, and then improves individual empathy for others.

\section{Research Prospects}

Nostalgia refers to the memory of past events or characters and feelings. There have been a lot of studies which have shown that nostalgia has a positive effect on the individual's physical and mental health, but nostalgia and pro-social behavior studies are relatively rare. Focusing on nostalgia and pro-social behavior has far-reaching theoretical and practical significance, on the one hand, it can extend the research directions in the area of nostalgia, on the other hand, nostalgia and pro-social behavior research contributes to social harmony and peace, doing pro-social behavior can also increase positive experiences and the positive evaluation of ourselves, it not only helps others but also benefits to givers. Given the nostalgia and pro-social behavior has just started, I believe that future research may continue the discussion further in following ways.

\subsection{Deepening Explore the Relevant Psychological Mechanism}

I discussed possible psychological mechanisms and theoretical explanations from three aspects: motivation, social identity and empathy. Because of psychological complexity, we should do more comprehensive studies to receive more systematic and comprehensive explanations, there are also many researchers discovered the potential of other possible variables. For example, Baldwin and others' [41] study found that nostalgia offered a window to the intrinsic self-concept, defined as a set of ideas, feelings, and beliefs about one's core and authentic attributes. Focusing on one's intrinsic self reduces personal concern with meeting external standards and expectations. And research shows that as people express their authentic selves, they also become more concerned with the welfare of others and are capable of empathy [42]. Empathy promotes altruism which is also considered to be a value of the authentic. In another study on nostalgia and money, Lasaleta [43] through 6 experimental study found that nostalgia could weaken people's desire for money. The researchers manipulated nostalgia through an advertisement perusal task or instructions to recall an autobiographical event. Measures of desire for money ranged from cognitive (willingness to pay for desired products, experiment 1; willingness to expend effort, experiment 5), to behavioral (dictator game, experiment 2), perceptual (coin size, experiment 6), and valuation (experiments 3 and 4). Results showed that nostalgic participants gave money to others whom they did not know nor even met, this was very similar to the financial assistance in our lives. Nostalgia is like a signal to promote social connectedness, the cue of social connectedness can shift people's motivations such that prioritizing and keeping control over money becomes less pressing. And existing research also found that money priming would decrease pro-social behaviors [11]. The nostalgia, which can weaken the desire of money, can indirectly ease the relationship? This is just one of our reasoning, which also needs research testing.

\subsection{Moderated Effects of Individual Differences}

\subsubsection{Nostalgic Propensity}

Some individuals show a higher propensity for nostalgia than others, individuals in the high-nostalgia-prone 
group are found to perceive the past more favorably and have a tendency to become more nostalgic than those in the low-nostalgia-prone group. Ford and Merchant [12] found that nostalgic propensity moderated the relationships between nostalgia and donor intention. Among low-nostalgia-prone consumers, nostalgic appeals for charity would yield higher levels of reactions (emotions and donation intentions) as compared to non-nostalgic appeals. Conversely, as high-nostalgia-prone individuals have a natural tendency to become nostalgic anyway, the authors are unlikely to find any difference in their emotional reactions to nostalgic appeals for charity as compared to non-nostalgic appeals.

\subsubsection{Attachment Type}

Attachment describes an innate behavior that individual seeks closeness to significant others (such as parents, spouses, etc.) to obtain protection, secure attachment can make individual trust others and are willing to give help to others and also receive help from others. Secure attachment enhances empathic responses and inhibits personal distress. Thompso and Gullone [44] found secure attachment styles prompted more pro-social behavior. Wildschut [7] found that nostalgia could enhance the individual's ability to provide emotional support to others, and when the attachment avoidance was low, this effect was even more apparent. Abeyta [45] found that the nostalgic memories of those low in avoidance were more likely to reflect a sense of being loved, trusted, and comforted by others than the nostalgic memories of those high in avoidance. In their view, individuals high in attachment avoidance were thought to eschew interpersonal relationships as a source of psychological security and, in consistent with this, the nostalgic memories of high-avoidance individuals contained fewer attachmentrelated references. Moreover, individuals with high attachment avoidance are also thought to value self-reliance [46], however, triggering participants' self-reliance will reduce pro-social behavior [11].

Therefore, when the attachment type is not the same, the content and emotion inspired by nostalgia are different, and different attachment styles also have different effects on pro-social behavior. So I think future researches of nostalgia and pro-social studies should take into account more individual differences like nostalgic propensity or attachment types.

\subsection{Refinement of the Nostalgia and Pro-Social Behavior Researches}

Research has some limitations about nostalgia and pro-social behavior, not only in terms of content, research methods are also single, future research should be improved in two ways.

First, researchers should use a variety of methods to invoke nostalgia. In ad spending study areas, there have been several methods of triggering nostalgia, including visual advertising, the smells and music [47]. Trigger on the nostalgia is too simple in the field of psychology, and most methods are asking the subjects according to instructions to recall nostalgia events. But this method is not common in our daily life, passive nostalgia caused by some environmental stimulus are more ordinary. When nostalgic environment and style changes, will the relationship between nostalgia and pro-social behavior change? Future research should expand the method to trigger the nostalgia, select more objective factors triggering nostalgia, which also helps to improve the external validity of the experiment.

Secondly, it is also necessary to refine the individual investigation of pro-social behavior. On one hand, studies of pro-social behavior including donation, helping, cooperation and acceptance, measurement of these variables are all self-reported test method in the laboratory, but behavioral intention is not the same as behavioral itself, we should use more real test method to replace the measurement of behavioral intentions.

On the other hand, in which circumstances nostalgia will influence pro-social behavior more effective? For example, when discussing the nostalgia reduced prejudices, we acknowledge that perceptions of mental illness vary considerably. For example, many people believe that people with schizophrenia are a danger to others, but far fewer believe that those with depression or eating disorders represent danger. Nostalgia may be most effective at improving intergroup attitudes where the target outgroup is relatively familiar to participants and perceived as relatively unthreatening.

\section{References}

[1] Batcho, K.I. (2013) Nostalgia: The Bittersweet History of a Psychological Concept. History of Psychology, 16, 165176. http://dx.doi.org/10.1037/a0032427

[2] Sedikides, C., Wildschut, T. and Baden, D. (2004) Nostalgia: Conceptual Issues and Existential Functions. In: Green- 
berg, J., Koole, S. and Pyszczynski, T., Eds., Handbook of Experimental Existential Psychology, Guilford Press, New York, 200-214.

[3] Hepper, E.G., Ritchie, T.D., Sedikides, C. and Wildschut, T. (2012) Odyssey’s End: Lay Conceptions of Nostalgia Reflect Its Original Homeric Meaning. Emotion, 12, 102-119. http://dx.doi.org/10.1037/a0025167

[4] Cheung, W.Y., Wildschut, T., Sedikides, C., Hepper, E.G., Arndt, J. and Vingerhoets, A.J. (2013) Back to the Future Nostalgia Increases Optimism. Personality and Social Psychology Bulletin, 39, 1484-1496. http://dx.doi.org/10.1177/0146167213499187

[5] Wildschut, T., Sedikides, C., Arndt, J. and Routledge, C. (2006) Nostalgia: Content, Triggers, Functions. Journal of Personality and Social Psychology, 91, 975-993. http://dx.doi.org/10.1037/0022-3514.91.5.975

[6] Xiao, F.Q., Zheng, Z.W. and Chen, Y.H. (2014) Theoretical Development of the Underlying Mechanism of Prosocial Behavior. Journal of Psychological Science, 37, 1263-1270.

[7] Carlo, G. and Randall, B.A. (2002) The Development of a Measure of Prosocial Behaviors for Late Adolescents. Journal of Youth and Adolescence, 31, 31-44. http://dx.doi.org/10.1023/A:1014033032440

[8] Gino, F. and Desai, S.D. (2012) Memory Lane and Morality: How Childhood Memories Promote Prosocial Behavior. Journal of Personality and Social Psychology, 102, 743-758. http://dx.doi.org/10.1037/a0026565

[9] Baker, S.M. and Kennedy, P.F. (1994) Death by Nostalgia: A Diagnosis of Context-Specific Cases. Advances in Consumer Research, 21, 169-174.

[10] Zhang, Q.P. and Kou, Y. (2011) The Dimension of Measurement on Prosocial Behavior: Exploration and Confirmation. Sociological Studies, 4, 105-121.

[11] Li, A.M., Peng, Y., Li, B. and Ling, W.Q. (2014) The Effects of Money Priming on Prosocial Behavior and Its Decision Mechanism. Advances in Psychological Science, 22, 845-856.

[12] Ford, J.B. and Merchant, A. (2010) Nostalgia Drives Donations: The Power of Charitable Appeals Based on Emotions and Intentions. Journal of Advertising Research, 50, 450-459. http://dx.doi.org/10.2501/S0021849910091592

[13] Zhou, X.Y., Wildschut, T., Sedikides, C., Shi, K. and Feng, C. (2012) Nostalgia: The Gift That Keeps on Giving. Journal of Consumer Research, 39, 39-50. http://dx.doi.org/10.1086/662199

[14] Stephan, E., Wildschut, T., Sedikides, C., Zhou, X.Y., He, W.M., Routledge, C., et al. (2014) The Mnemonic Mover: Nostalgia Regulates Avoidance and Approach Motivation. Emotion, 14, 545-561. http://dx.doi.org/10.1037/a0035673

[15] Codding, B. (2014) Seeking New Horizons: The Motivation behind Volunteers Serving Overseas.

[16] De Cremer, D. and Tyler, T.R. (2005) Managing Group Behavior: The Interplay between Procedural Justice, Sense of Self, and Cooperation. Advances in Experimental Social Psychology, 37, 151-218. http://dx.doi.org/10.1016/S0065-2601(05)37003-1

[17] Thau, S., Aquino, K. and Poortvliet, P.M. (2007) Self-Defeating Behaviors in Organizations: The Relationship between Thwarted Belonging and Interpersonal Work Behaviors. Journal of Applied Psychology, 92, 840-847. http://dx.doi.org/10.1037/0021-9010.92.3.840

[18] Van Dijke, M., Wildschut, T., Leunissen, J.M. and Sedikides, C. (2015) Nostalgia Buffers the Negative Impact of Low Procedural Justice on Cooperation. Organizational Behavior and Human Decision Processes, 127, 15-29. http://dx.doi.org/10.1016/j.obhdp.2014.11.005

[19] Wildschut, T., Bruder, M., Robertson, S., van Tilburg, W.A. and Sedikides, C. (2014) Collective Nostalgia: A GroupLevel Emotion That Confers Unique Benefits on the Group. Journal of Personality and Social Psychology, 107, 844863. http://dx.doi.org/10.1037/a0037760

[20] Puhl, R.M. and Heuer, C.A. (2009) The Stigma of Obesity: A Review and Update. Obesity, 17, 941-964. http://dx.doi.org/10.1038/oby.2008.636

[21] Turner, R.N., Wildschut, T. and Sedikides, C. (2012) Dropping the Weight Stigma: Nostalgia Improves Attitudes toward Persons Who Are Overweight. Journal of Experimental Social Psychology, 48, 130-137. http://dx.doi.org/10.1016/j.jesp.2011.09.007

[22] Aron, A., Aron, E.N., Tudor, M. and Nelson, G. (1991) Close Relationships as Including Other in the Self. Journal of Personality and Social Psychology, 60, 241-253. http://dx.doi.org/10.1037/0022-3514.60.2.241

[23] Turner, R.N., Wildschut, T., Sedikides, C. and Gheorghiu, M. (2013) Combating the Mental Health Stigma with Nostalgia. European Journal of Social Psychology, 43, 413-422. http://dx.doi.org/10.1002/ejsp.1952

[24] Batson, C.D. and Oleson, K.C. (1991) Current Status of the Empathy-Altruism Hypothesis. In: Clark, M.S., Ed., Review of Personality and Social Psychology, Vol. 12, Prosocial Behavior, Sage, Newbury Park, 62-18.

[25] Gray, J.A. (1990) Brain Systems That Mediate both Emotion and Cognition. Cognition and Emotion, 4, 269-288. http://dx.doi.org/10.1080/02699939008410799 
[26] Mikulincer, M., Shaver, P.R., Gillath, O. and Nitzberg, R.A. (2005) Attachment, Caregiving, and Altruism: Boosting Attachment Security Increases Compassion and Helping. Journal of Personality and Social Psychology, 89, 817-839. http://dx.doi.org/10.1037/0022-3514.89.5.817

[27] Sierra, J.J. and McQuitty, S. (2007) Attitudes and Emotions as Determinants of Nostalgia Purchases: An Application of Social Identity Theory. Journal of Marketing Theory and Practice, 15, 99-112. http://dx.doi.org/10.2753/MTP1069-6679150201

[28] Tajfel, H. (1982) Social Psychology of Intergroup Relations. Annual Review of Psychology, 33, 1-39. http://dx.doi.org/10.1146/annurev.ps.33.020182.000245

[29] Zhang, Y.R. and Zuo, B. (2006) Social Identity Theory and It's Development. Advances in Psychological Science, 14, 475-480.

[30] Tajfel, H.E. (1978) Differentiation between Social Groups: Studies in the Social Psychology of Intergroup Relations. Academic Press, Waltham.

[31] Tidwell, M.V. (2005) A Social Identity Model of Prosocial Behaviors within Nonprofit Organizations. Nonprofit Management and Leadership, 15, 449-467. http://dx.doi.org/10.1002/nml.82

[32] Mael, F. and Ashforth, B.E. (1992) Alumni and Their Alma Mater: A Partial Test of the Reformulated Model of Organizational Identification. Journal of Organizational Behavior, 13, 103-123. http://dx.doi.org/10.1002/job.4030130202

[33] O’Reilly, C.A. and Chatman, J. (1986) Organizational Commitment and Psychological Attachment: The Effects of Compliance, Identification, and Internalization on Prosocial Behavior. Journal of Applied Psychology, 71, 492-499. http://dx.doi.org/10.1037/0021-9010.71.3.492

[34] Volkov, M., Morgan, M.J. and Summers, J. (2008) The Role of Nostalgia in Determining Consumers' Sport Team Identification. Proceedings of the 6th Annual Sport Marketing Association Conference (SMA 2008), Sport Marketing Association, 89-103.

[35] Funk, D.C. and James, J.D. (2006) Consumer Loyalty: The Meaning of Attachment in the Development of Sport Team Allegiance. Journal of Sport Management, 20, 189-217.

[36] Batson, C.D., Fultz, J. and Schoenrade, P.A. (1987) Distress and Empathy: Two Qualitatively Distinct Vicarious Emotions with Different Motivational Consequences. Journal of Personality, 55, 19-39. http://dx.doi.org/10.1111/j.1467-6494.1987.tb00426.x

[37] Batson, C.D. and Coke, J.S. (1981) Empathy: A Source of Altruistic Motivation for Helping. In: Rushton, J.P. and Sorrentino, R.M., Eds., Altruism and Helping Behavior: Social, Personality, and Developmental Perspectives, Lawrence Erlbaum Associates, Hillsdale, 167-187.

[38] Batcho, K.I. (1998) Personal Nostalgia, World View, Memory, and Emotionality. Perceptual and Motor Skills, 87, 411-432. http://dx.doi.org/10.2466/pms.1998.87.2.411

[39] Zhou, X.Y., Sedikides, C., Wildschut, T. and Gao, D.G. (2008) Counteracting Loneliness: On the Restorative Function of Nostalgia. Psychological Science, 19, 1023-1029. http://dx.doi.org/10.1111/j.1467-9280.2008.02194.x

[40] Cordaro, F. (2011) The Relationship between Nostalgia, Social Exclusion, and Empathy. Doctoral Dissertation, University of Southampton, Southampton.

[41] Baldwin, M., Biernat, M. and Landau, M.J. (2015) Remembering the Real Me: Nostalgia Offers a Window to the Intrinsic Self. Journal of Personality and Social Psychology, 108, 128-147. http://dx.doi.org/10.1037/a0038033

[42] Koltko-Rivera, M.E. (2006) Rediscovering the Later Version of Maslow's Hierarchy of Needs: Self-Transcendence and Opportunities for Theory, Research, and Unification. Review of General Psychology, 10, 302-317. http://dx.doi.org/10.1037/1089-2680.10.4.302

[43] Lasaleta, J.D., Sedikides, C. and Vohs, K.D. (2014) Nostalgia Weakens the Desire for Money. Journal of Consumer Research, 41, 713-729. http://dx.doi.org/10.1086/677227

[44] Thompson, K.L. and Gullone, E. (2008) Prosocial and Antisocial Behaviors in Adolescents: An Investigation into Associations with Attachment and Empathy. Anthrozoös, 21, 123-137. http://dx.doi.org/10.2752/175303708X305774

[45] Abeyta, A.A., Routledge, C., Roylance, C., Wildschut, T. and Sedikides, C. (2015) Attachment-Related Avoidance and the Social and Agentic Content of Nostalgic Memories. Journal of Social and Personal Relationships, 32, 406-413.

[46] Shaver, P.R. and Mikulincer, M. (2002) Attachment-Related Psychodynamics. Attachment \& Human Development, 4, 133-161. http://dx.doi.org/10.1080/14616730210154171

[47] Li, B., Ma, H.Y., Li, A.M. and Ling, W.Q. (2015) The Trigger, Research Paradigm and Measurement of Nostalgic. Advances in Psychological Science, 23, 1289-1298. 